Iranian Quarterly Journal of Breast Disease. 2019; 12(2):17-25

\section{Original Article \\ Relationships between Body Mass Index, Serum Leptin Levels, and 17 $\beta$-Estradiol in Postmenopausal Women with Breast Cancer: A Case-Control Study}

\author{
Tahmasebi Fard $Z^{1^{*}}$ \\ ${ }^{1}$ Biology group, Roudehen Branch, Islamic Azad of University, Roudehen, Iran
}

Receive: $2018 / 12 / 28$ Accepted: 2019/05/08

*Corresponding Author: Zahra Tahmasebi Fard ztahmasebi@ riau.ac.ir

Ethics Approval: IR.IAU.TMU.REC.1395.292

\begin{abstract}
Introduction: There is a close relationship between the incidence of breast cancer and fat intake in different populations. Overweight and obesity during menopause can increase the risk of breast cancer in women. Hormones like estrogen and leptin are factors that affect the growth and proliferation of breast cells. The main purpose of this study was to evaluate the relationships between body mass index (BMI) and serum levels of leptin and $17 \beta$-estradiol in postmenopausal women with breast cancer.
\end{abstract}

Methods: Seventy-nine postmenopausal women with breast cancer and Seventy-nine healthy postmenopausal women, aged 50-75 years, were recruited for the study. After obtaining written informed consent and demographic data, blood samples were taken from all participants to assess the serum concentrations of hormones using ELISA.

Results: The mean BMI was $25.59 \pm 0.34 \mathrm{~kg} / \mathrm{m}^{2}$ for the cancer group, $23.21 \pm 0.22 \mathrm{~kg} / \mathrm{m}^{2}$ for the control group $(P=0.001)$. The difference in serum concentration of 17 beta-estradiol between the cancer group and the control group was significant $(54.27 \pm 1.91$ and $46.44 \pm 1.36 \mathrm{pg} / \mathrm{ml}$, respectively, $P=0.001)$. The mean serum leptin level was significantly lower in the cancer group $(41.05 \pm 3.10 \mathrm{ng} / \mathrm{ml})$ than in the control group $(53.05 \pm 4.83,53 \mathrm{ng} / \mathrm{ml})(P=0.036)$.

Conclusion: Body mass index in both groups was significantly and positively correlated with serum levels of $17 \beta$-estradiol, but there was no significant correlation between BMI and serum leptin concentration. Postmenopausal women with BMI $>25$ and high serum concentrations of $17 \beta$-estradiol are probably susceptible to breast cancer.

Keywords: Breast Cancer, Postmenopausal Women, Estrogen, Leptin 


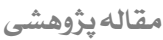

بررسى ارتباط بين شاخص توده بدنى با سطح سرمى ليتين و

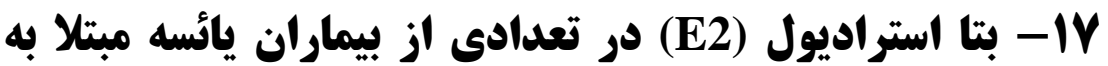

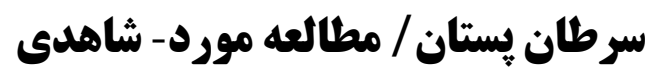

زهرا طهماسبى فردا" ' كروه زيست شناسى، دانشكده علوم بايه، واحد رودهن دانشگاه آزاد اسلامى، رودهن، ايران
فصلنامه بيمارى هاى يستان ايران IrQA I Ir(r): IV-ro

\section{جكيده}

مقدمه: ارتباط نزديكى بين شيوع سرطان يستان و مصرف خربى در جمعيتهاى مختلف كزارش

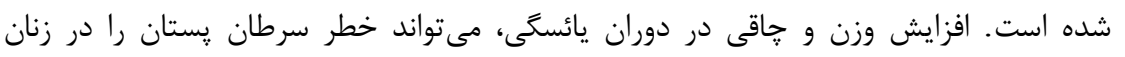

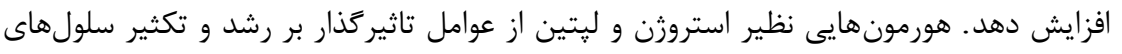

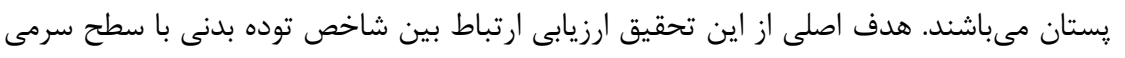

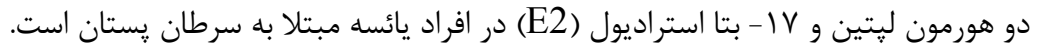

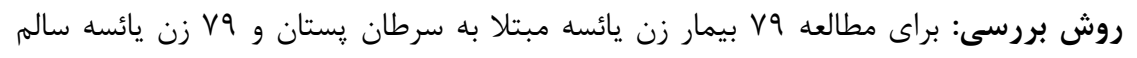

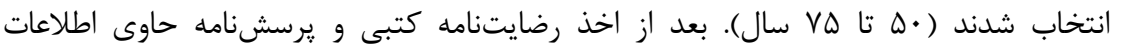

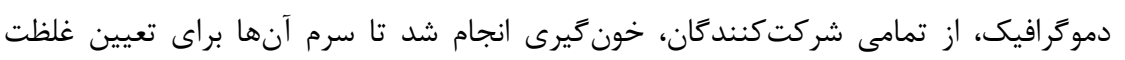

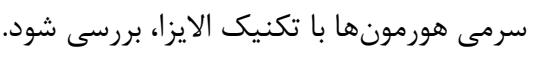
يافتهها: ميانكَين شاخص توده بدنى در كروه سرطانى و كروه كنترل به ترتيب

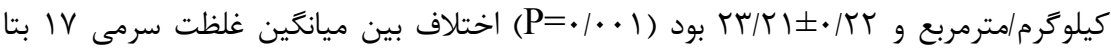

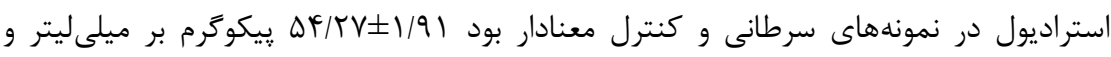

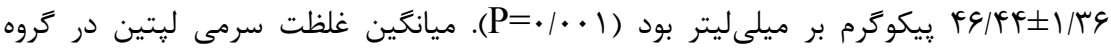

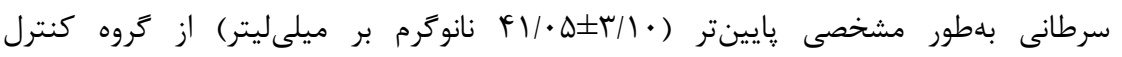

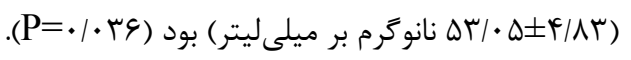

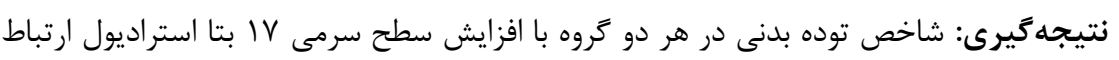

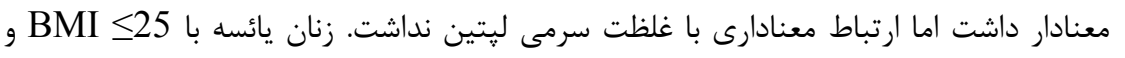

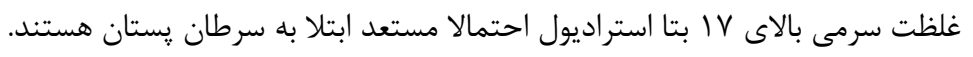
|وازههاى كليدى: سرطان يستان، يائسكى، استرورن، ليتين

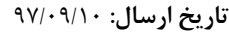

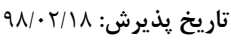

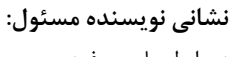

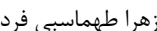
ztahmasebi@riau.ac.ir 
و سرطان اندومتر را سبب شود (با). VIV إ) بتا استراديول، مقدمه

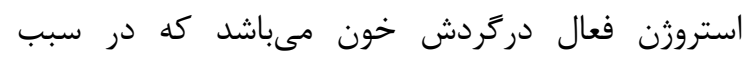
شناسى سرطان يستان، نقش مهمى دارد. غلظت بالاى آن آن

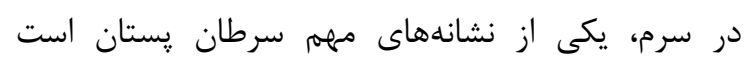

مطالعات اخير نشان دادهاند كه هورمونهاى ليتين و وران

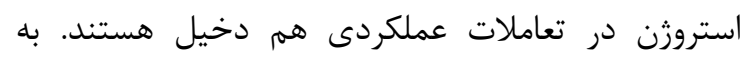

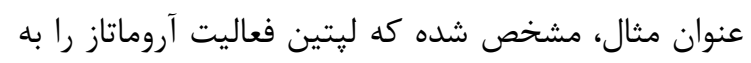

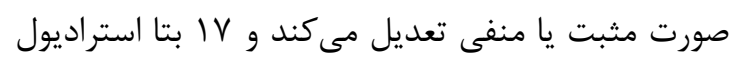
(E2)

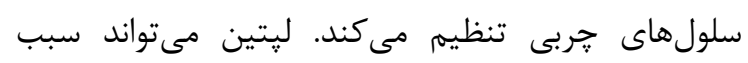

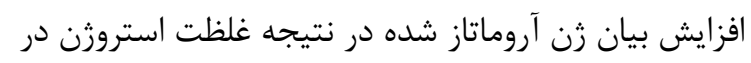

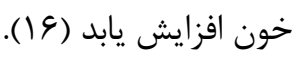

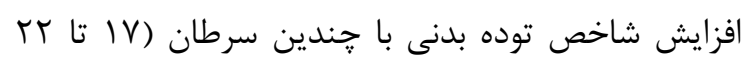

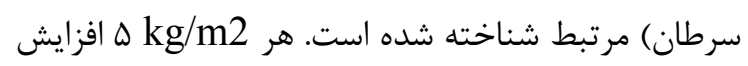

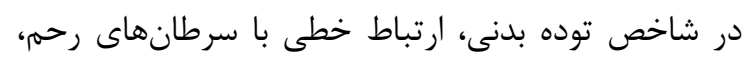

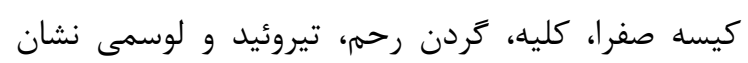

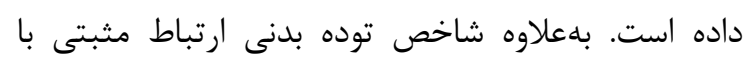

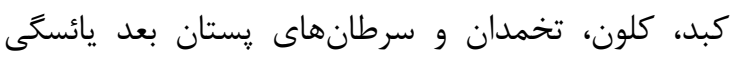

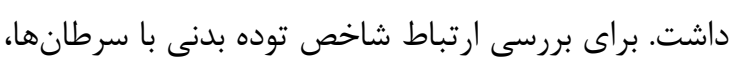

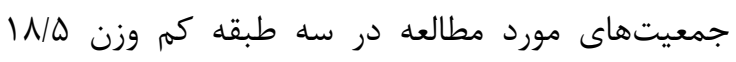

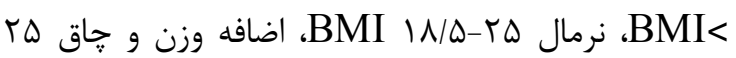

$$
\text { BMI }
$$

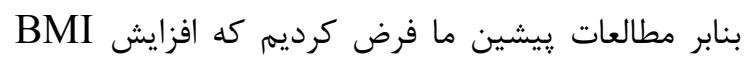

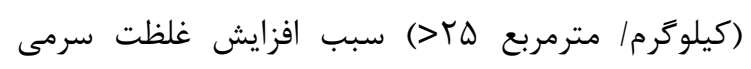

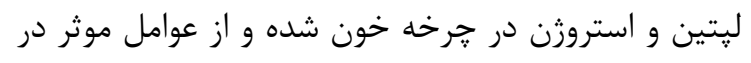

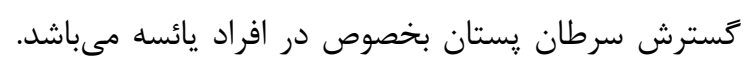
در اين تحقيق شاخص توده بدنى افراد (در دو كروه

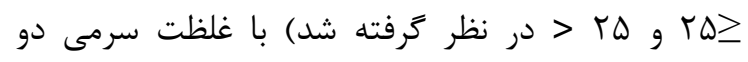

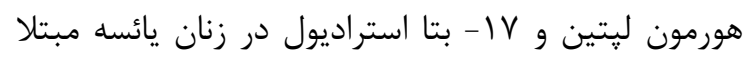

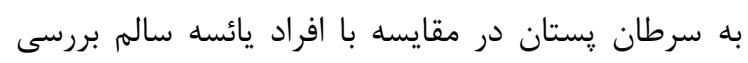

شد.

\section{مواد و روشها}

اين مطالعه بر اساس روش مورد- شاهدى بود. حجم نمونه

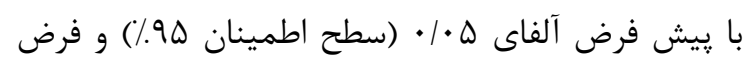

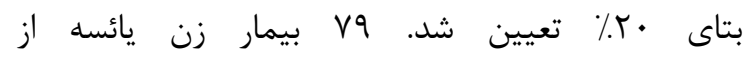

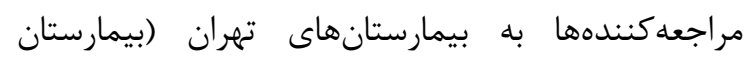

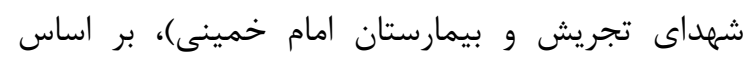

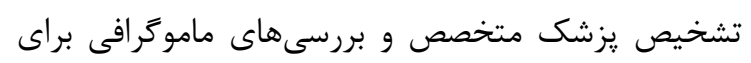

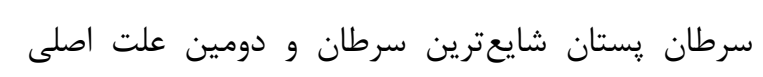

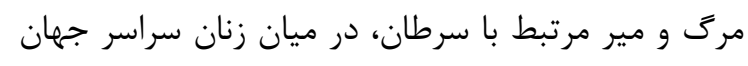

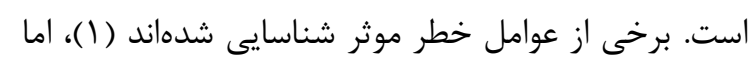

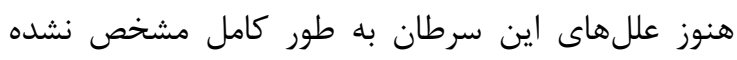

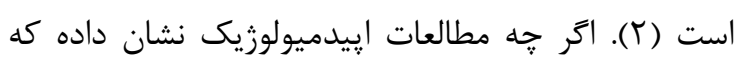

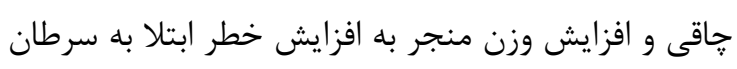

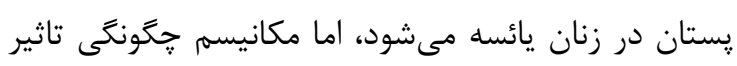

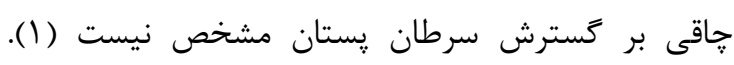

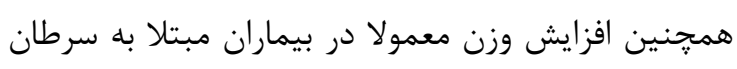

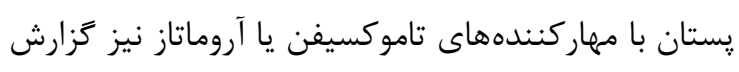

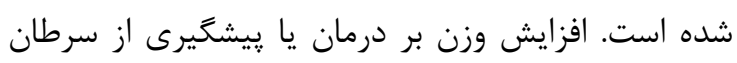

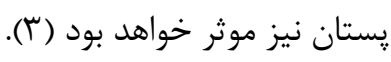

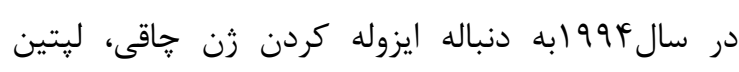

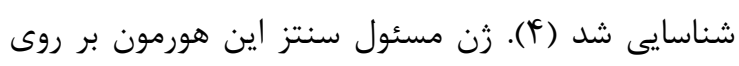

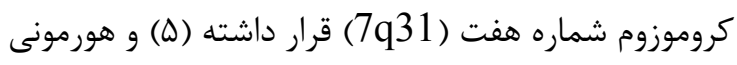

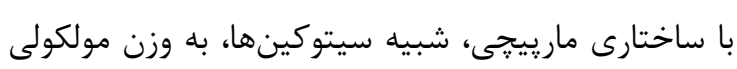

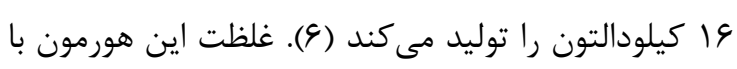

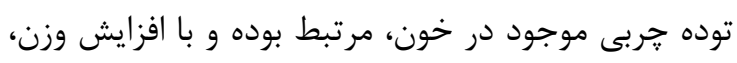

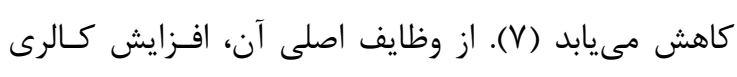

مصرفى، كاهش توليد ATP و كاهش اشتهاست (N).

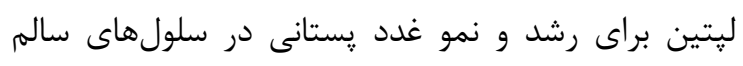
انسان ضروريست اما مشخص شده كه افزايش اين هورمون فئن

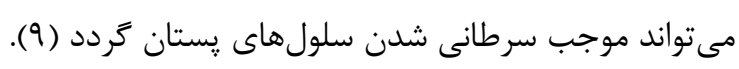

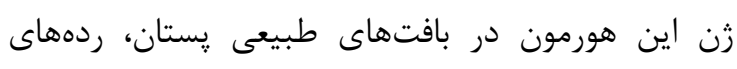

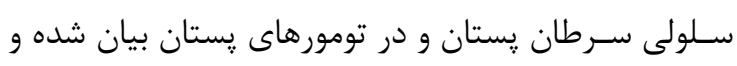

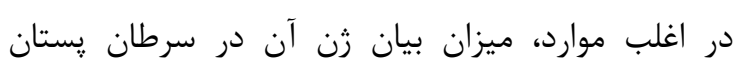

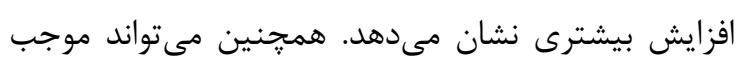

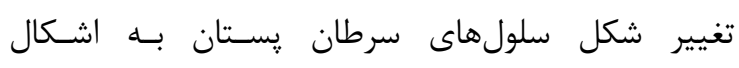

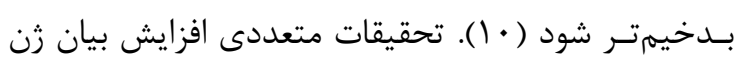

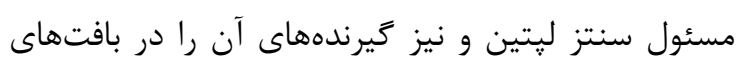

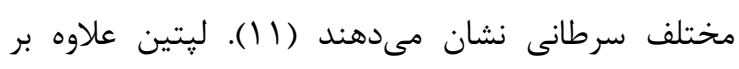

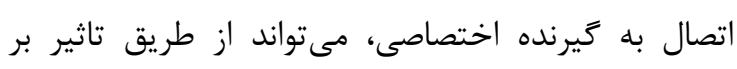

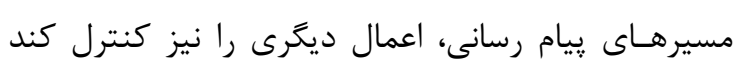

استروزن هورمون فيزيولوزى ضرورى براى رشد، تمايز و

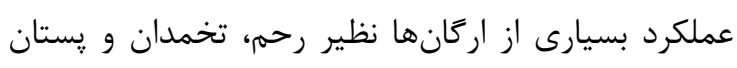

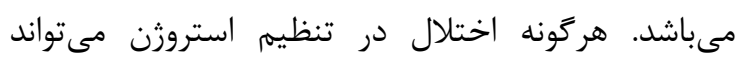
״يامدهاى پاتولوزيكى جون يوكى استخوان، سرطان يستان 
كَرفتند تا بهطور كامل لخته خون، تشكيل شود. سيس

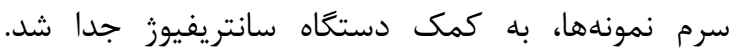

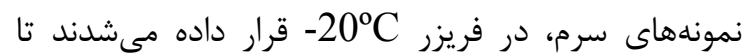

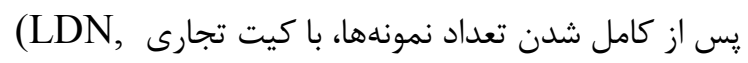
غلظت سرمى ليتين با Nordhorn, Germany)

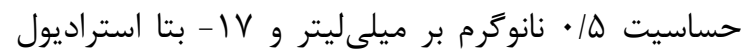
(DiaMetra, Italy)

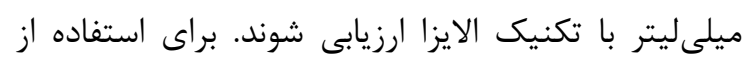

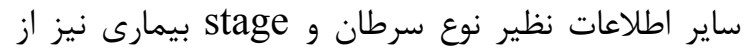
كزارش گياتولوزى بيماران استفاده شد.

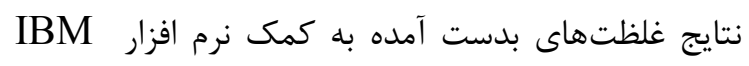

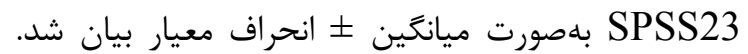

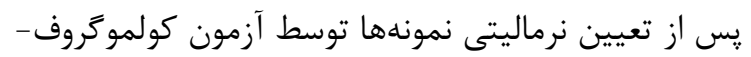

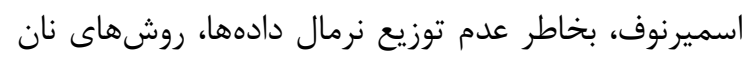

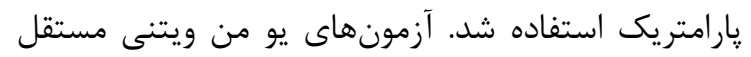
براى مقايسه ميانگين متغيرهاى كمى در دو كروه بيمار و و

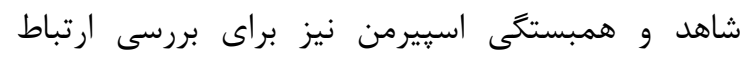

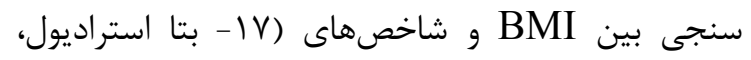
ليتين، ...) بين دو گروه استفاده شد. سطح معنى إدارى كمتر از هـ/• كر نظر كرفته شد.

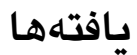

از تمامى افراد اطلاعاتى مربوط به سن، قد، وزن، دريافت

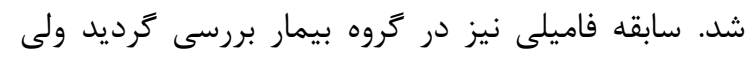

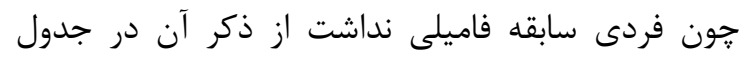

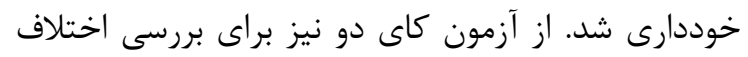

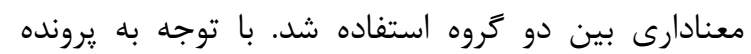

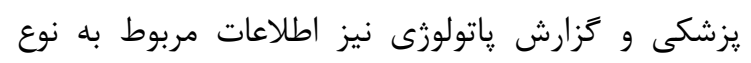

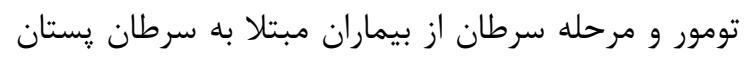

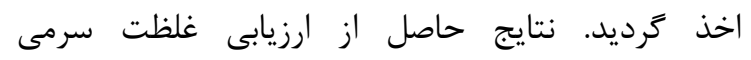
هورمونها نيز در جدول آلنآ آورده شده است.

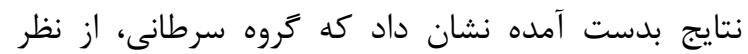

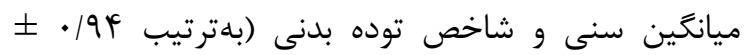

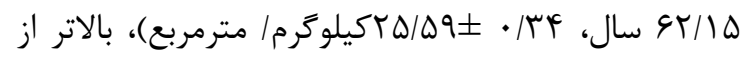
كروه شاهد (بلترتيب

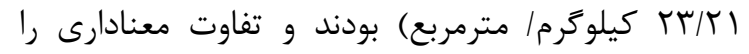
نشان مى دادند.
مطالعه انتخاب شدند. معيارهاى ورود به مطالعه در مورد افراد بيمار، تاييد ابتلا به سرطان يستان (نداشتن سرطان

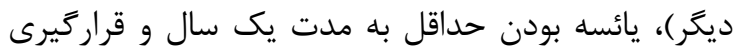

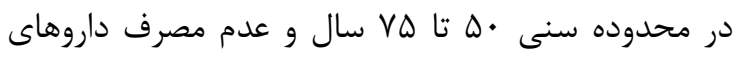

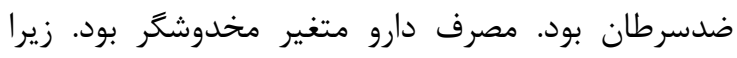
داروهايى نظير تاموكسيفن كه علايم يائسكى از جمله

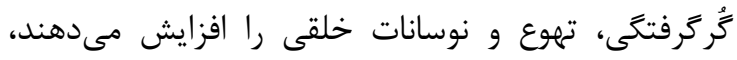

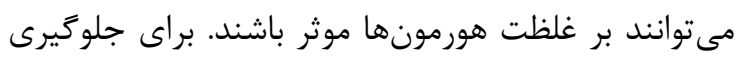

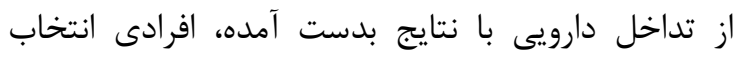

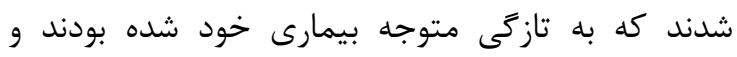

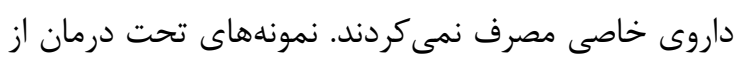

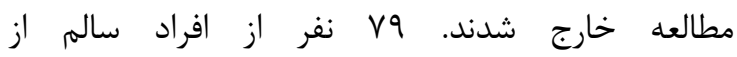

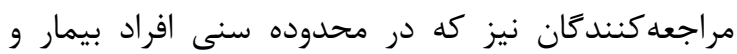

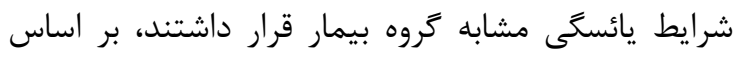

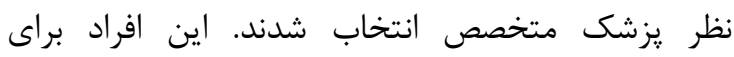
بررسىهاى ساليانه وضعيت سلامت خود به بيمارستانهاى

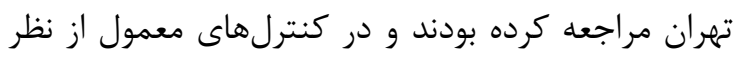

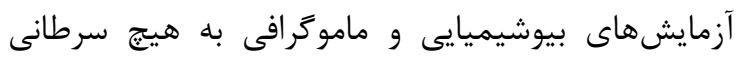

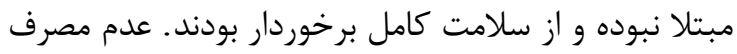

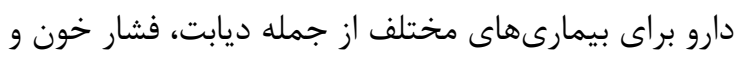

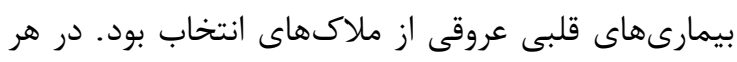

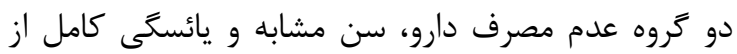

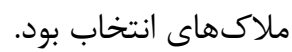
از تمامى افراد رضايتنامه كرفته شد و و شركت آنهاب آنها در

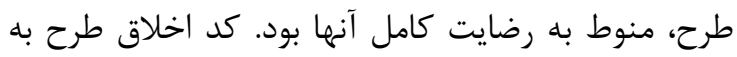
شماره IR.IAU.TMU.REC.1395.292 از كميته اخلاق در يزوهش دانشخاه آزاد اسلامى واحد يزشكى

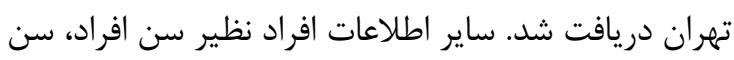

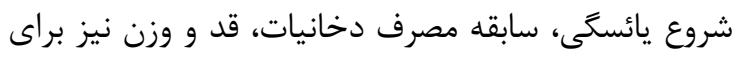

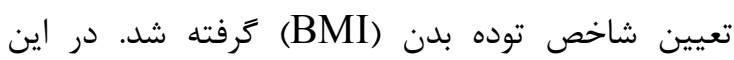

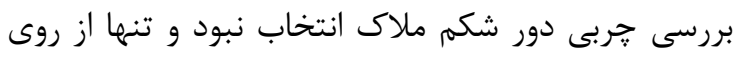
قد و وزن BMI افراد محاسبه شد. از محدوديتهاى يزوهش، عدم ثبت غذايى به منظور بررسى تفاوت در

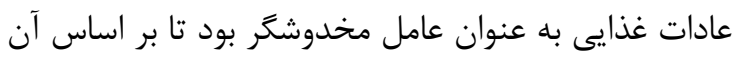

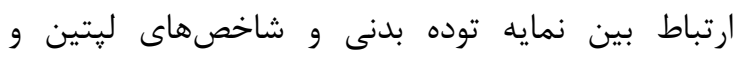
استراديول بررسى شود.

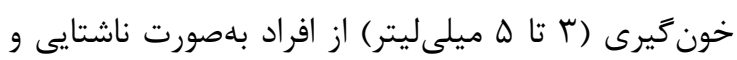
با شرايط يكسان صورت گرفت. تمامى نمونههاى خون،

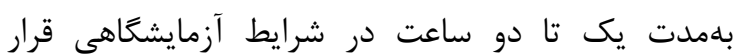


جدول ا: اطلاعات دموكرافيكى و باتولوزيكى افراد شركت كننده در طرح

\begin{tabular}{|c|c|c|c|c|}
\hline P Value & كروه كنترل (vq نفر) & كروه بيمار ( Vq نفر) & بات & خصوم \\
\hline \multirow{4}{*}{$\cdot 1 \cdot \cdot 1$} & $\Delta V(/ V Y / / \Delta)$ & $r T(/ . F \cdot \mid 01)$ & • •ه تا •ع سال & \multirow{4}{*}{ 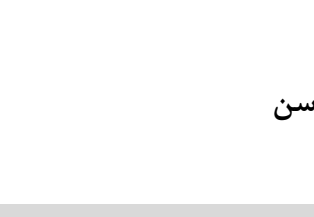 } \\
\hline & $19(/ / T \cdot / r \Delta)$ & $r F(/ F r / \cdot r)$ & ا 1 تا •V سال & \\
\hline & $9(/ / V / 4 \cdot)$ & $1 \pi(/ .19 / 49)$ & اV سال و بالاتر & \\
\hline & $\Delta \Delta / F \uparrow \pm \cdot / \Lambda \Delta$ & $G T / 1 \Delta \pm \cdot / 94$ & ميانكَين \pm انحراف معيار & \\
\hline \multirow{3}{*}{$\cdot 1 \cdot \cdot 1$} & 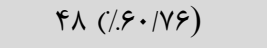 & rI $(/ . r q / T r)$ & $<r \Delta$ & \multirow{3}{*}{ BMI } \\
\hline & $r \cdot(/ T \Delta / r T)$ & $\Delta 9(/ V F / q \Lambda)$ & $r \Delta \geq$ & \\
\hline & $T r / T I \pm \cdot / r T$ & $r \Delta / \Delta q \pm \cdot / r F$ & ميانگين I انحراف معيار & \\
\hline$\cdot 1 \cdot \cdot 1$ & $r q / F \uparrow \pm 1 / r q$ & $\Delta F / F V \pm 1 / 91$ & ميانگين 土 انحراف معيار & Vg/ml بتا استراديول \\
\hline$\cdot 1 \cdot r 4$ & $\Delta r / \cdot \Delta \pm r / \Lambda r$ & $|\psi| / \cdot \Delta \pm r / l \cdot$ & ميانكَين 土 انحراف معيار & ليتين ng/ml \\
\hline \multirow{4}{*}{-} & \multirow{4}{*}{-} & $T F(/ . r \cdot / r \Lambda)$ & سرطان مهاجم لوبولار' & \multirow{4}{*}{ وع سرطان } \\
\hline & & $r V(/ . \& \& \mid \Lambda \uparrow)$ & سرطان مهاجم مجارى؟ & \\
\hline & & If $(/ . \mathrm{V} / \mathrm{V} r)$ & سرطان مجارى درجا؟ & \\
\hline & & $f(/ . \Delta / \cdot 9)$ & سرطان لوبولى درجاء & \\
\hline \multirow{5}{*}{-} & \multirow{5}{*}{-} & $19(/ . T \cdot / T r)$ & I مرحله I & \multirow{5}{*}{ مرحله بيمارى } \\
\hline & & $1 \cdot(/ .1 Y / 99)$ & مرحله II & \\
\hline & & $r \cdot(/ T \Delta / r r)$ & مرحله II/III & \\
\hline & & $r T(/ T V / \Lambda \Delta)$ & مرحله III & \\
\hline & & $11(/ .14 / 94)$ & متاستاز & \\
\hline
\end{tabular}

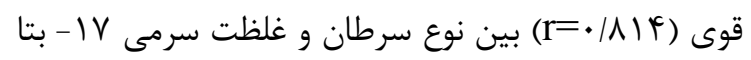

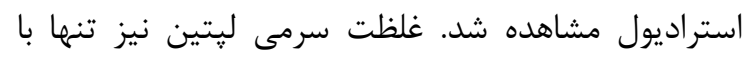

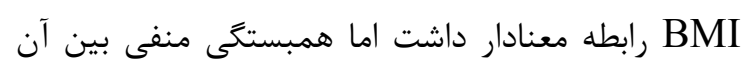

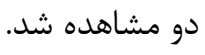

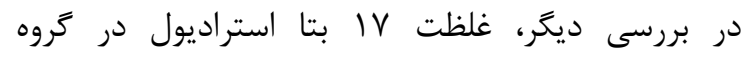

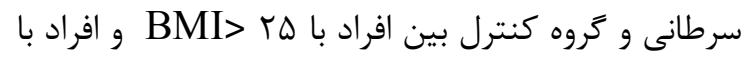
BMI S مورد تجزيه و تحليل آمارى قرار كرفت. نتايج

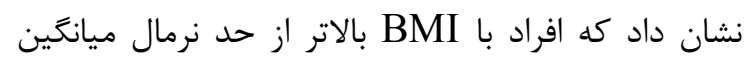

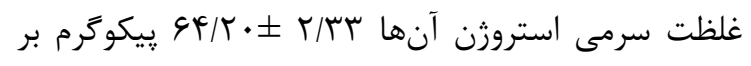

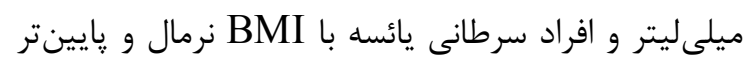

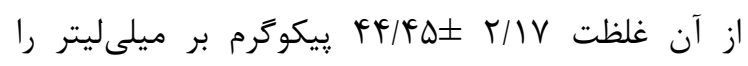

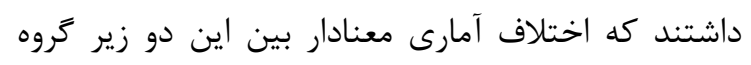

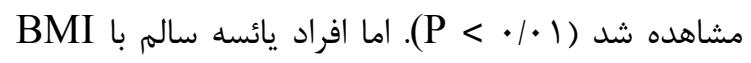

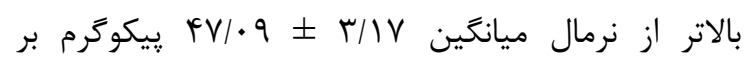

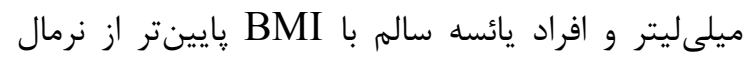
ميانكين 1/49 غلظت سرمى استروزن نشان دادند كه معنادار نبود

$$
\text { . }(\mathrm{P}=\cdot / \wedge \mathrm{r} \mathrm{V})
$$

\footnotetext{
${ }^{1}$ Invasive Lobular Carcinoma (ILC)

${ }^{2}$ Invasive Ductal Carcinoma (IDC)

${ }^{3}$ Ductal Carcinoma in Situ (DCIS)

${ }^{4}$ Lobular Carcinoma in Situ (LCIS)
}

غلظت سرمى هورمون لِتين در گروه بيمار با ميانگين

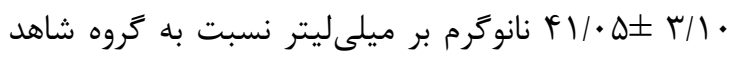

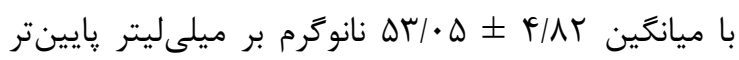
بود اما در مورد VY IV - بتا استراديول

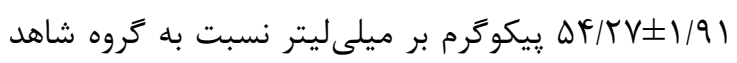

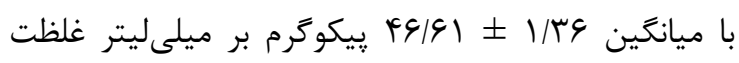

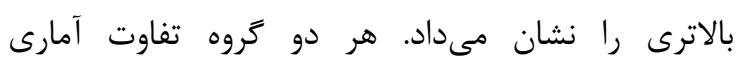

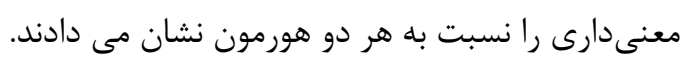

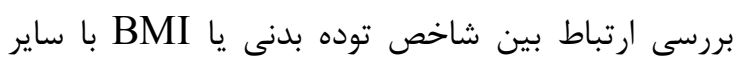

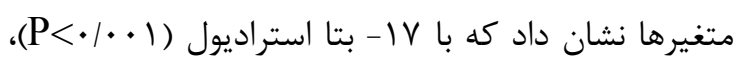

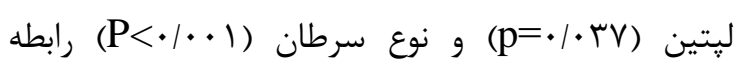

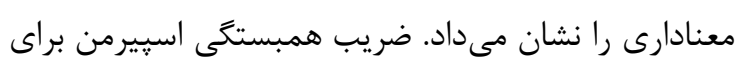
BMI

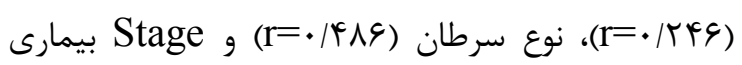
مثبت بود. اما با غلظت سرمى ليتين ضريب (r=//199)

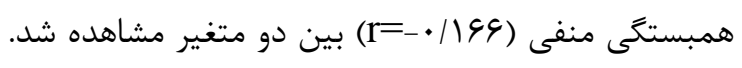
غلظت سرمى IV

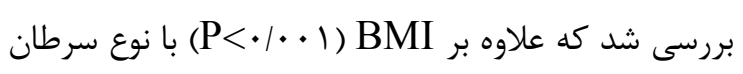

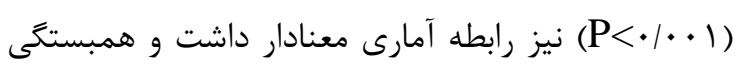


در درمان سرطان يستان از روش هورمون درمانى، جهت

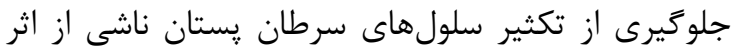

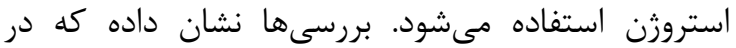

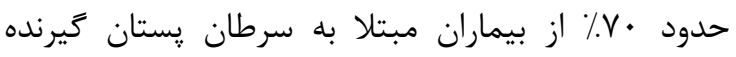

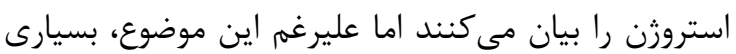

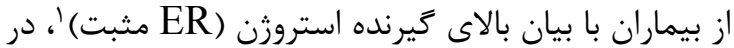

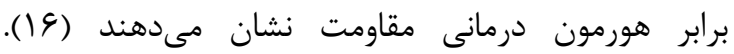
مطالعات نشان داده كه كيرنده ليتين و گيرنده استروزن در بافت بدخيم يستان و در سلولهاى سرطانى يستان با ليان هم بيان مىشوند (1) (1). بنابراين احتمالا مسيرهاى انتقال

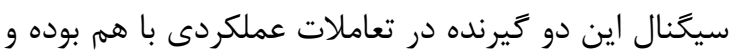
به بيشرفت تومور كمك مى كنند. بهعلاوه، ليتين ارتباط متقابلى با קندين مسير انتقال ييام، از جمله استروزن،

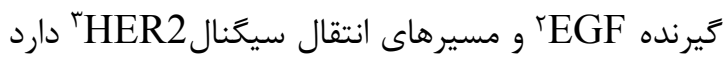
كه مى تواند از اهداف درمانى سرطان يستان باشد (19 (1).

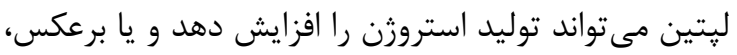

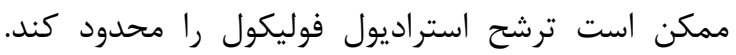
بنابراين فرض مىشود كه BMI ممكن است خطر سرطان يستان را از راه هورمونى تحت تاثير قرار دهد. از طرف

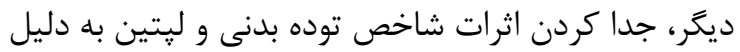

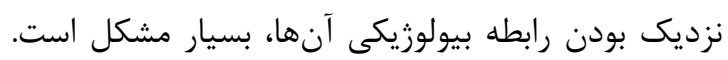

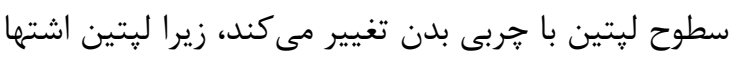

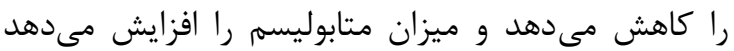

ارتباط جاقى با ساير فاكتورهاى خطر براى زنان يائسه مبتلا به سرطان קستان مورد تاييد مىباشد و افزايش استروزن درونى بخاطر خاقى، از عوامل مسبب بالا رفتن

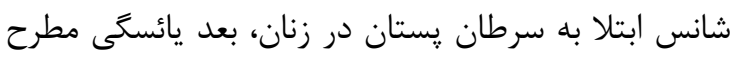

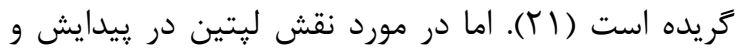
ييشرفت سرطان يستان نتايج متناقضى وجود دارد و

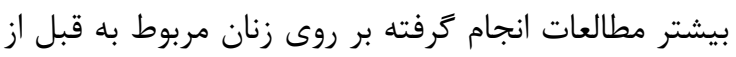
دوران يائسگى است. در مطالعه حاضر غلظت سرمى لِّين در گروه سرطانى

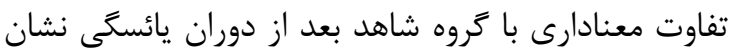

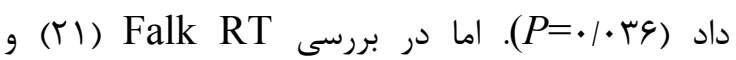
Petridou E

${ }^{1}$ Estrogen receptor (ER)

${ }^{2}$ Epidermal growth factor (EGF)

${ }^{3}$ human epidermal growth factor receptor 2 (HER2)
همين بررسى براى غلظت سرمى ليتين نيز انجام گرفت.

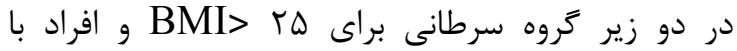
BMI $\leq r \Delta$

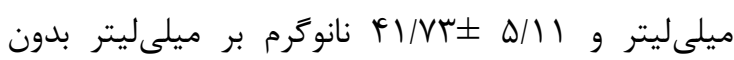
اختلاف معنادار مشاهده شد (

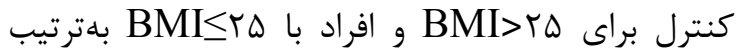
غلظتها 9/VF

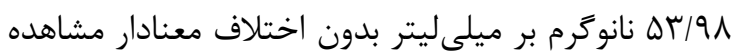

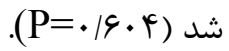

\section{بحث}

در بررسىهاى انجام كَفته شاخص توده بدنى به دو بخش

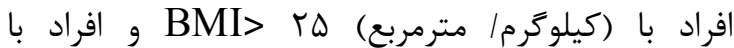
BMI $\leq r \Delta$ و كنترل به دو زير كروه تقسيمبندى شدند. نتايج اين بررسى اختلاف معنادار بين غلظت سرمى استرورن و افزايش BMI را در كروه سرطانى نشان معى داد. اما زير كروهها براى غلظت سرمى لِّين تفاوتى را نشان ندادند. اما بررسى بين دو گروه بيمار و كنترل نشان داد كهان لهان

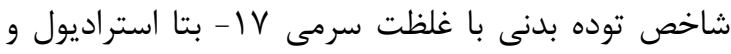

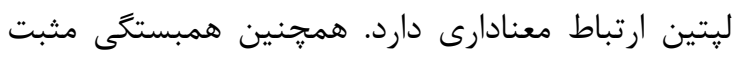
بين BMI و IV - بتاستراديول در دو كروه مورد مطالعه

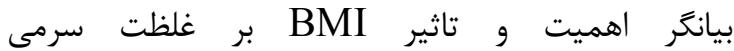
هورمونهاست. همبستگى بين BMI و ليتين در دو كروه مورد مطالعه منفى بود. از آنجا كه ليتين از هورمونهاى

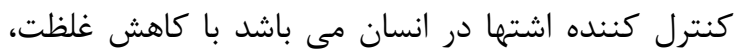

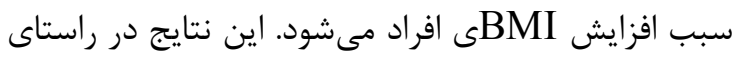
يروهشهاى قبلى ارايه شده است. در زنان خاق يّ از يائسگى، سطوح هورمون استروزن بالا

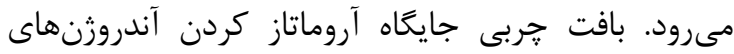

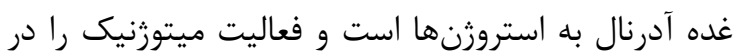
بافت קستان به كمك اتصال به گيرندههاى استروزن تحريك مى كند (r|). جندين مطالعه إِيدميولوزيكى نشان

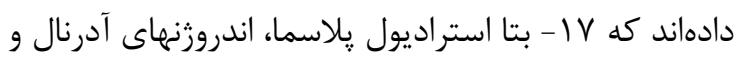
سطح تستوسترون در زنان مبتلا به نئويلاسم نسبت به اديه

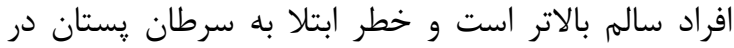

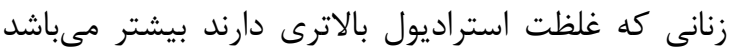


تحقيق قبلى مشخص كرديد كه أ|٪ افزايش ابتلا به

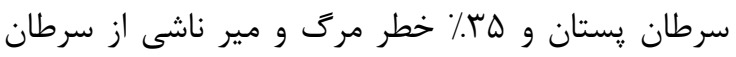
در زنان جاق نسبت به زنان با وزن نرمال، بيشتر ديده

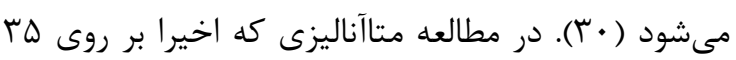

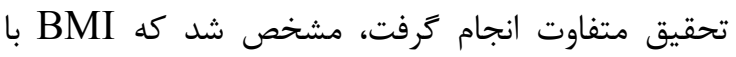

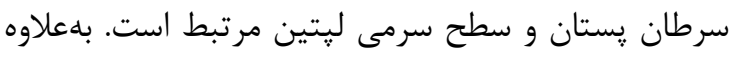

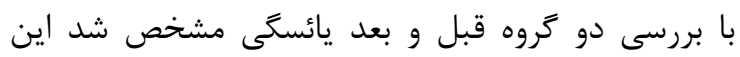

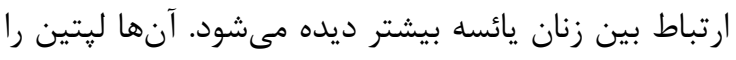

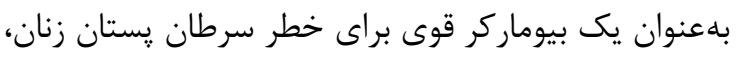

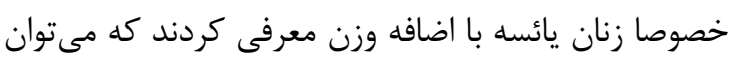

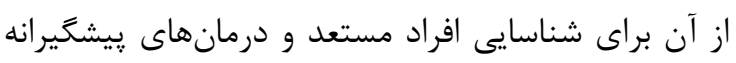

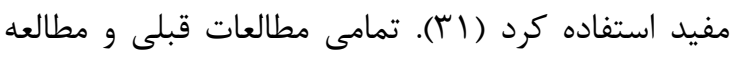

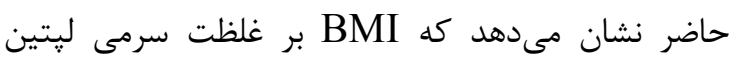
موثر است. اما در اين بررسى همبستخى منفى بين BMI

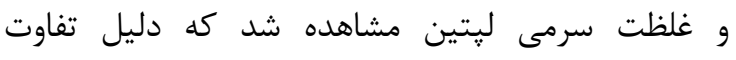

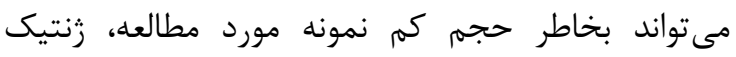

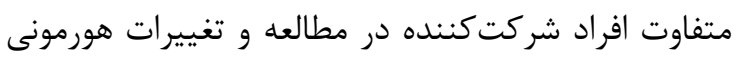

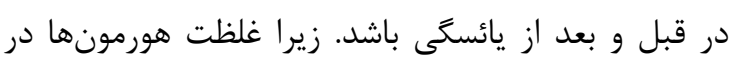

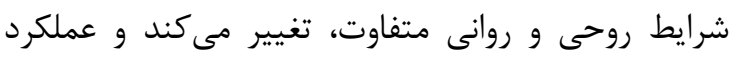

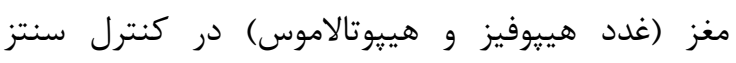

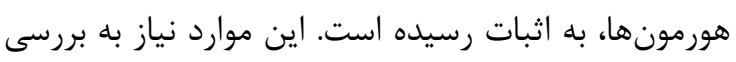

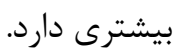

\section{نتيجهكيرى}

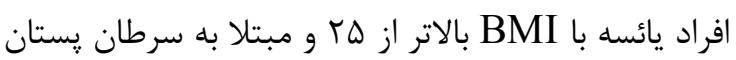

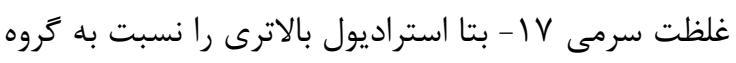

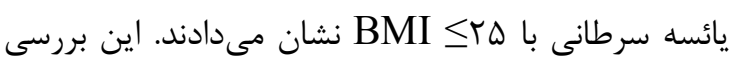

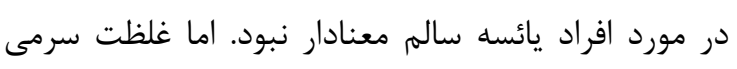

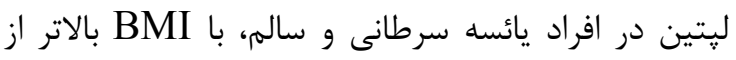

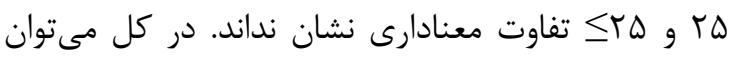

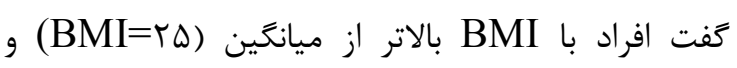

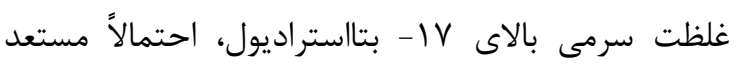

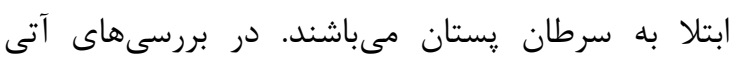

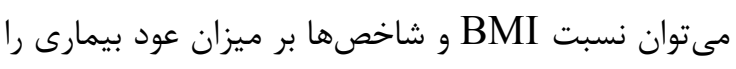
بررسى نمود. بهعلاوه با ثبت غذايى، تفاوت نداخت در عاديت عادات

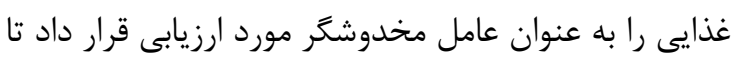

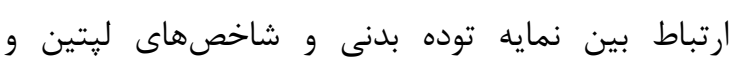
استراديول بر اساس آن سنجيده شود. توده بدن
ليتين با سرطان يستان زنان قبل از دوران يائسكى، انجام

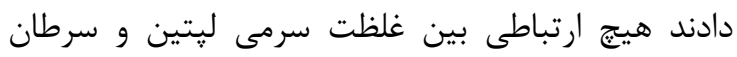

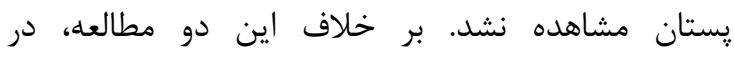

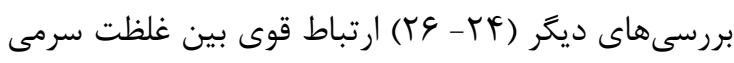

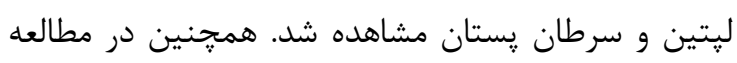
Chen DC

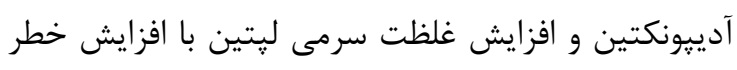

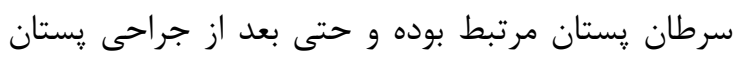

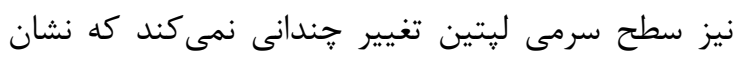

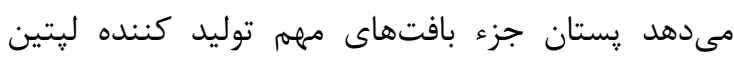

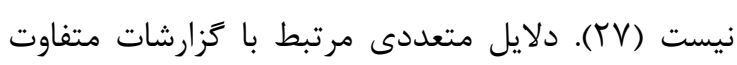

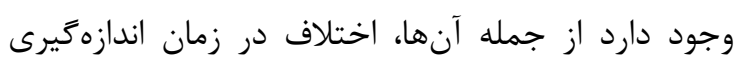

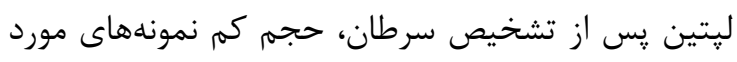

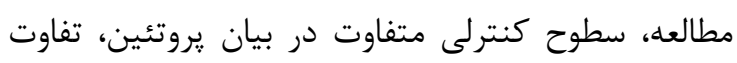

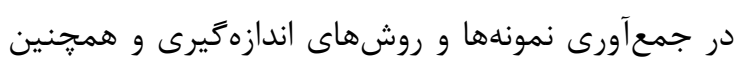

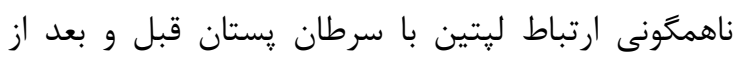

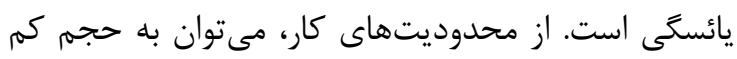

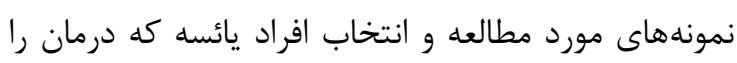

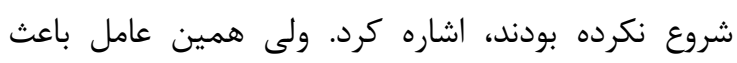
تفاوت اين يزوهش با ساير تحقيقهاى مرتبط با اين بادي موضوع مىباشد.

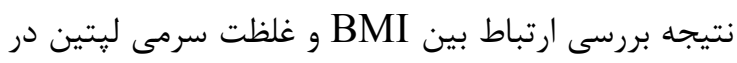

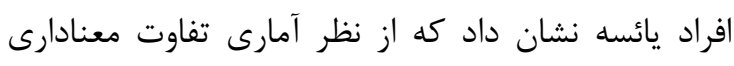

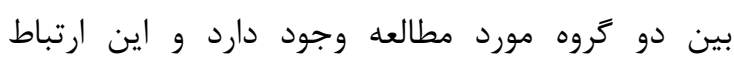

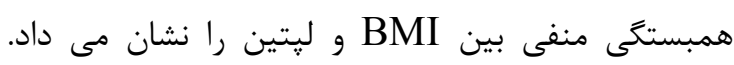

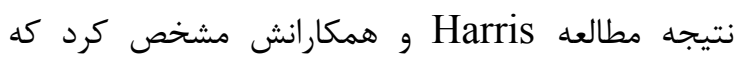

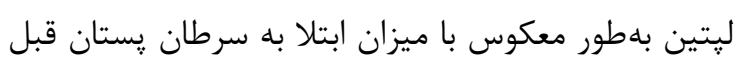

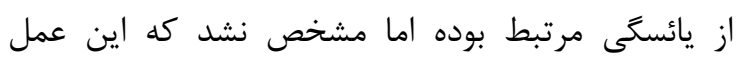

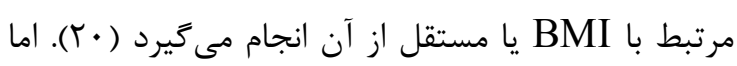

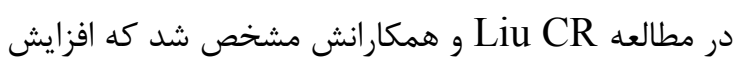

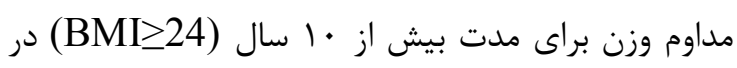

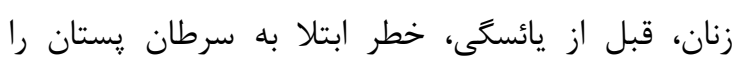

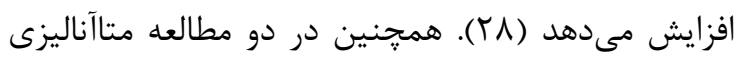

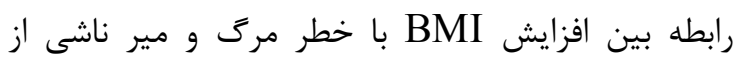

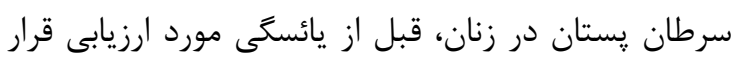

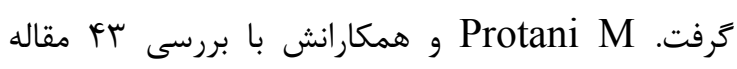

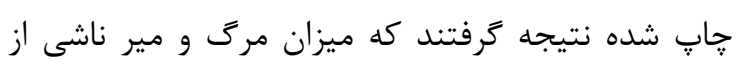

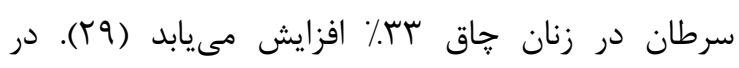
مطالعه Chan, D.S و همكارانش نيز بان بررسى دران 
تجريش كه در جمع آورى نمونه همكارى داشتند، تشكر و

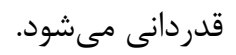

$$
\begin{aligned}
& \text { تعارض منافع } \\
& \text { نويسندكان اعلام مىدارند كه هيج تعارض منافعى در }
\end{aligned}
$$

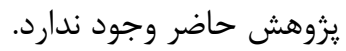

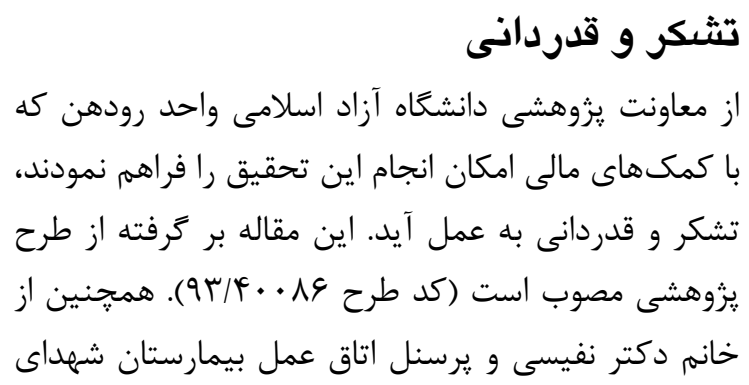

\section{References}

1. Niu J, Jiang L, Guo W, Shao L, Liu Y and Wang L. The Association between Leptin Level and Breast Cancer: A Meta-Analysis. PLoS One. 2013; 8(6): e67349.

2. Wanjun $\mathrm{Y}$, Xingcong $\mathrm{M}$, Xiaoyan $\mathrm{G}$, and Zhang Sh. Association Between Leptin (2548G/A) Genes Polymorphism and Breast Cancer Susceptibility . A Meta-Analysis. Medicine (Baltimore). 2016; 95(4): e2566.

3. Sestak I, Harvie M, Howell A, Forbes JF, Dowsett M, Cuzick J. Weight change associated with anastrozole and tamoxifen treatment in postmenopausal women with or at high risk of developing breast cancer. Breast Cancer Res Treat. 2012; 134(2):727-34.

4. Zoladz J, Konturek S, Duda K, Majerczak J, Sliwowski Z, Grandys M, et al. Effect of Moderate Incremental Exercise, Performed. Journal of Physiology and Pharmacology 2005; 56(1): 63-85.

5. Snoussi K, Strosberg AD, Bouaouina N, Ahmed SB, Helal AN, Chouchane L. Leptin and leptin receptor polymorphisms are associated with increased risk and poor prognosis of breast carcinoma. BMC Cancer 2006; 6(1): 38 .

6. Ahima RS, Flier JS. Adipose tissue as an endocrine organ. Trends in Endocrinology \& Metabolism 2000; 11(8): 327-32.

7. Vona-Davis L, Rose DP. Adipokines as endocrine, paracrine, and autocrine factors in breast cancer risk and progression. EndocrineRelated Cancer. 2007; 14(2):189-206.

8. Widmaier E, Raff H, KT S. Regulation of organic metabolism and energy balance. In: Vander's human physiology: the mechanisms of body function. 10th ed. New York: McGraw-Hill. 2006 ;(13): 637-9.

9. Cleary M, Grande J, Maihle N. Effect of high fat diet on body weight and mammary tumor

latency in MMTV-TGF- $\alpha$ mice. International Journal of Obesity 2004; 28(8): 956-62.

10. Lorincz A, Sukumar S. Molecular links between obesity and breast cancer. EndocrineRelated Cancer 2006;13(2): 279-92.

11. Cleary M, Grande J, Maihle N. Effect of high fat diet on body weight and mammary tumor latency in MMTV-TGF- $\alpha$ mice. International Journal of Obesity 2004; 28(8): 956-62.

12. Fiorio E, Mercanti A, Terrasi M, Micciolo R, Remo A, Auriemma A, et al. Leptin/HER2 crosstalk in breast cancer: in vitro study and preliminary in vivo analysis. BMC Cancer 2008; 8(1): 305.

13. Nilsson S, Mäkelä S, Treuter E, Tujague M, Thomsen J, Andersson G, and et al. Mechanisms of Estrogen Action. Physiological Reviews 2001; 81(4):1535- 65.

14. Travis RC, Key TJ. Oestrogen exposure and breast cancer risk. Breast Cancer Research 2003; 5(5):239-49.

15. Menzaghi C, Ercolino T, Di Paola R, Berg AH, Warram JH, Scherer PE, Trischitta V, Doria A. A haplotype at the adiponectin locus is associated with obesity and other features of the insulin resistance syndrome. Diabetes 2002; 51(7): 2306-12.

16. Kyong Yom Ch, Kyung-Min L, Wonshik H, Sung-Won K, Hee Sung K, Byung M and et al. Leptin as a Potential Target for Estrogen Receptor-Positive Breast Cancer. J Breast Cancer. 2013; 16(2): 138-145.

17. Bhaskaran K, Douglas I, Forbes H, dosSantos-Silva I, Leon DA, Smeeth L. Bodymass index and risk of 22 specific cancers: a population-based cohort study of 5.24 million UK adults. Lancet. 2014; 384(9945):755-65.

18. Hu X, Juneja SC, Maihle NJ, Cleary MP. Leptin: a growth factor in normal and malignant breast cells and for normal 
mammary gland development. J Natl Cancer Inst. 2002;94:1704-1711.

19. Surmacz E. Obesity hormone leptin: a new target in breast cancer? Breast Cancer Res. 2007;9(1):301.

20. Harris HR., Tworoger Sh S., Hankinson S E., Rosner B A., and Michels K B. Plasma leptin levels and risk of breast cancer in premenopausal women. Cancer Prev Res (Phila). 2011; 4(9): 1449-56.

21. Suzuki R, Rylander-Rudqvist T, Ye W, Saji $\mathrm{S}$, Wolk A. Body weight and postmenopausal breast cancer risk defined by estrogen and progesterone receptor status among Swedish women: A prospective cohort study. Int J Cancer. 2006; 119(7):1683-9.

22. Falk R, Brinton L, Madigan M, Potischman $\mathrm{N}$, Sturgeon $\mathrm{S}$, Malone $\mathrm{K}$, et al. Interrelationships between serum leptin, IGF-1, IGFBP3, C-peptide and prolactin and breast cancer risk in young women. Breast Cancer Res Treat 2006; 98(2):157-65.

23. Petridou E, Papadiamantis Y, Markopoulos C, Spanos E, Dessypris N, Trichopoulos D. Leptin and insulin growth factor I in relation to breast cancer (Greece). Cancer Causes Control. 2000;11(5):383-8.

24. Hou WK, Xu YX, Yu T, Zhang L, Zhang $\mathrm{WW}, \mathrm{Fu} \mathrm{CL}$, and et al. Adipocytokines and breast cancer risk. Chin Med J (Engl). 2007;120(18):1592-6.

25. Woo H-Y, Park H, Ki C-S, Park YL, Bae WG . Relationships among serum leptin, leptin receptor gene polymorphisms, and breast cancer in Korea. Cancer Lett 2006;237(1):13742.

26. Wu MH, Chou YC, Chou WY, Hsu GC, Chu $\mathrm{CH}$, Yu CP, et al.Circulating levels of leptin, adiposity and breast cancer risk. Br J Cancer 2009; 100(4):578-82.

27. Chen DC, Chung YF, Yeh YT, Chaung HC, Kuo FC, Fu OY, and et al. Serum adiponectin and leptin levels in Taiwanese breast cancer patients. Cancer Lett. 2006;237(1):109-14. Epub 2005 Jul 12.

28. Liu CR, Li Q, Hou C, Li H, Shuai P, Zhao M, Zhong XR, Xu ZP, Li JY. Changes in Body Mass Index, Leptin, and Leptin Receptor Polymorphisms and Breast Cancer Risk. DNA Cell Biol. 2018;37(3):182-188.

29. Protani M, Coory M, Martin J.H. Effect of obesity on survival of women with breast cancer: Systematic review and meta-analysis. Breast Cancer Res. Treat. 2010; 123(3): $627-$ 35.

30. Chan D.S, Vieira A.R, Aune D, Bandera E.V, Greenwood D.C, McTiernan A and et al. Body mass index and survival in women with breast cancer-systematic literature review and metaanalysis of 82 follow-up studies. Ann. Oncol. 2014; 25(10): 1901-14.

31. Pan H, Deng LL, Cui JQ, Shi L, Yang YC, Luo $\mathrm{JH}$, and et al. Association between serum leptin levels and breast cancer risk: An updated systematic review and meta-analysis. Medicine (Baltimore). 2018;97(27):e11345. 